\title{
Balkan Medical Journal is Now a Member of Committee on Publication Ethics
}

We are proud to announce to our readers, authors and reviewers that the Balkan Medical Journal's application for membership of the Committee on Publication Ethics (COPE) one of the most important organizations on publication ethics in the world (1) has been accepted. For many years the editorial board of the Balkan Medical Journal has adhered to the principles of COPE and has followed and implemented its guidelines and flowcharts, and this formal recognition by COPE of the journal's ethical stance is an important first step towards the future. Membership will allow the Balkan Medical Journal and its editorial board to consult COPE on ethical issues (1).

Following acceptance of our membership of COPE, we performed the audit ethical evaluation chart which is provided to member journals by COPE (1). This indicated that the Balkan Medical Journal already complies with most of COPE's ethical standards. We have noted the gaps in our current editorial policy and instructions to authors and these will be revised before publication of the first issue of 2014 .

The ethical commitments our journal has made, and our membership of several important international organizations for scientific publication including the International Council of Medical Journal Editors (ICMJE), the World Association of Medical Editors (WAME), the Council of Science Editors (CSE), the European Association of Science Editors (EASE) and now COPE, will be help to inform the journal's policies, improve its quality and integrity, and thus to serve its readers, authors and ultimately the population at large, better. We would like to thank our readers and authors in advance for respecting the ethical stance of the Balkan Medical Journal and hope that the revised guidelines will help to prevent potential breaches.

\section{Cem UZUN, MD}

Editor-in-Chief, Balkan Medical Journal

Department of Otolaryngology, Trakya University Faculty of Medicine, Edirne, Turkey

\section{References}

1. COPE - Committee on Publication Ethics. http://publicationethics.org/ (access: 30 November 2013). 